\title{
CLASSE, CULTURA E EXPERIÊNCIA NA OBRA DE E. P. THOMPSON: CONTRIBUIÇÕES PARA A PESQUISA EM EDUCAÇÃO ${ }^{1}$
}

\author{
Célia Regina Vendramini ${ }^{2}$ \\ Lia Tiriba ${ }^{3}$
}

\begin{abstract}
RESUMO
Visando contribuir com as pesquisas em educação, o objetivo desse artigo é reunir elementos teórico-metodológicos presentes na obra do historiador marxista inglês Edward P. Thompson. Nos marcos do materialismo histórico, aborda-se, especificamente, as análises do autor acerca da classe e consciência de classe, da experiência histórica e da cultura como questões fundamentais para apreensão da totalidade social. As classes sociais, a luta de classes e a consciência são compreendidas de forma articulada, como fenômeno histórico e como formação econômica, política e cultural. Ressalta-se o grande valor que o autor atribui aos estudos empíricos e que a análise da experiência, gerada na vida material, contribui para o entendimento das diversas formas de organização da vida social e do sentido histórico das atuais experiências coletivas de trabalhadores, suas raízes históricas e suas possibilidades, considerando no movimento real da sociedade, a dialética passado, presente e futuro.
\end{abstract}

Palavras-chave: E. P. Thompson; classes sociais; consciência de classe; experiência; cultura.

\section{CLASS, CULTURE AND EXPERIENCE IN THE WORK OF E. P. THOMPSON: CONTRIBUTIONS TO RESEARCH IN EDUCATION}

\begin{abstract}
Aiming to contribute to research in education, the objective of this paper is to gather theoretical and methodological elements present in the work by the english marxist historian Edward P. Thompson. Within the framework of historical materialism, it is approached, specifically, analysis by the author about the class and class awareness, historical experience and culture as key issues for apprehension of social totality. Social classes, class struggle and consciousness are understood in a coordinated manner, as a historical phenomenon and economic, political and cultural formation. It is emphasized the great value that the author attributes to empirical studies and that the analysis of the experience, generated in the material life, contributes to the understanding of the various forms of organization of social life and the historical sense of the current collective experiences of workers, its historical roots and its possibilities, considering the actual movement of society, the dialectic past, present and future.
\end{abstract}

Keywords: E. P. Thompson; social classes; class awareness; experience; culture. 
(...) é essencial manter presente no espírito o fato de os fenômenos sociais e culturais não estarem 'à reboque', seguindo os fenômenos econômicos a distância: eles estão em seu surgimento, presos na mesma rede de relações. (Thompson, 2001, p. 208)

Por que o debate sobre classes sociais permanece atual e mantém o seu vigor? O que significa dizer que a classe é uma formação tanto econômica como cultural? Seria possível identificar os fios que entrelaçam economia e cultura na tessitura das relações sociais? Por que, historicamente, a cultura popular se constitui como forma de manifestação e afirmação de um modo de vida e, ao mesmo tempo, como expressão de resistência a outras maneiras de fazer e pensar o mundo? Quais as relações existentes entre trabalho, educação e cultura? Como entendemos os nexos entre experiência e educação? Estas são algumas questões de pesquisa necessárias para a compreensão do processo histórico e dos desafios da atualidade, de maneira a considerar a totalidade social como unidade do diverso.

Todo modo de produção da existência humana nasce no interior daquele que já não é capaz de responder às exigências da vida material. O que se torna hegemônico contém, ainda que de forma submersa, os resquícios de antigas formas de produzir a vida social, as quais perduram no tempo/espaço, tornam-se dependentes, mas não necessariamente desaparecem. Como um conjunto de códigos, padrões, normas, conhecimentos, crenças, valores e criações materiais que regulam as formas de sociabilidade nos processos de trabalho, entendidos como processos de criação e recriação da realidade humano-social, as culturas do trabalho vão se constituindo no contexto das relações sociais de produção, determinadas, em grande medida, pela classe social que mantém o poder material e simbólico. Imersas no sistema capitalista, nos dias atuais, outras culturas do trabalho se manifestam nas experiências marcadas pela resistência econômica e cultural à produção capitalista. Indo ao encontro da palavra economia, do grego Oikos (casa) e nemo (eu distribuo, eu administro) e da palavra cultura (cultivar, criar, cuidar, tomar conta), podemos dizer que na economia popular (Tiriba, 2001), o objetivo do trabalho não é a reprodução do capital, mas a reprodução ampliada da vida. Lembramos as experiências dos quilombolas, caiçaras, ribeirinhos, além dos indígenas e outros povos e comunidades tradicionais situadas na Ásia, África, nas Américas (México, Peru, Bolívia, Equador) que, por serem milenares, não nasceram como resposta à pobreza ou à marginalização imposta pelo capital.

Ainda que de forma contraditória, também é distinta da cultura do capital, a organização do trabalho e da vida que se plasma no interior de uma cooperativa e outras instâncias de produção da vida no Movimento dos Trabalhadores Rurais Sem Terra - MST e nas diversas associações que compõem a Via Campesina, por exemplo. Buscando saídas coletivas para a sobrevivência, trabalhadores sem-terra vivem a contradição de organizar experiências de autogestão, de cooperativas de produção, de produção agroecológica no interior de relações marcadas pela apropriação privada da produção e pela subsunção do trabalho ao capital. (Vendramini, 2008)

O mesmo pode ser verificado em grupos de produção comunitária, em cooperativas populares, fábricas ocupadas e recuperadas pelos trabalhadores e demais experiências de produção associada que nascem para driblar a crise do emprego ou se constituem como instâncias de poder popular em momentos revolucionários, quer sob regime de controle operário ou autogestão. Protagonizadas pela classe trabalhadora do campo e da cidade, entre as experiências históricas de produção associada nas quais economia e cultura 
caminharam na contramão do capital destacam-se a Comuna de Paris (1871), os Soviets de representantes operários, camponeses e soldados na Rússia (1905 e 1917), a Guerra Civil Espanhola (1936-1939), os conselhos operários de Turim, Itália (1919-1921), Iugoslávia (1950), Polônia (1956, 1970) e a Revolução dos Cravos em Portugal (1974). Em âmbito latino-americano, temos Cuba (1959), Chile (1972) e Nicarágua (1979), além de curtas experiências vividas na Bolívia e Peru e a dos indígenas em Chiapas (desde 1994). No Brasil, especialmente no campo, é importante lembrar as experiências do Quilombo dos Palmares (segunda metade do século XVII), da República de Canudos (1896), Cadeirão de Santa Cruz do Deserto (1920), as Ligas Camponesas (1950), destacando-se a criação da Sociedade Agrícola e Pecuária de Plantadores de Pernambuco - SAPPP (1954), com a participação de Francisco Julião.

Para o historiador Edward P. Thompson, "toda contradição é um conflito de valor, tanto quanto um conflito de interesse (...) toda luta de classes é ao mesmo tempo luta acerca de valores" (Thompson, 1981, p. 189-190). Os motins da fome que ocorreram na Inglaterra ao longo do século XVIII e começo do século XIX, contribuem para evidenciar a imbricação do econômico e do cultural, considerados por esse autor como uma das manifestações da economia moral das multidões (Idem, 1998). Para ele, na análise histórica, sociológica ou política, "é essencial manter presente no espírito o fato de os fenômenos sociais e culturais não estarem 'a reboque', seguindo os fenômenos econômicos à distância: eles estão, em seu surgimento, presos na mesma rede de relações” (Thompson, 2001, p. 208).

Nos marcos do materialismo histórico, a análise de E. P. Thompson acerca da classe social e da consciência de classe como fenômeno histórico e como formação econômica, política e cultural, ajuda-nos a compreender o atual processo de constituição da classe trabalhadora, sua identidade, suas lutas, sua experiência e seu sentido histórico. Thompson compreende que a classe e a consciência de classe vão formando-se juntas na experiência: é uma formação imanente. Tal compreensão pode ser observada na análise que faz do período 1790 a 1830, quando se forma a classe operária inglesa. Sua análise considera o modo de vida característico dos trabalhadores, que está associado com um modo de produção, e os valores partilhados pelos que viveram durante a Revolução Industrial.

Como um historiador marxista contemporâneo e, portanto, tendo como eixo de análise o movimento real da sociedade, na sua singularidade e na sua totalidade, Thompson traz à superfície aspectos do processo histórico, até então pouco estudados. Entre eles, são de grande relevância nas suas obras, a experiência histórica e a cultura popular, geradas na própria vida e que permitem tornar visível o lugar do sujeito coletivo no processo de trabalho e nos movimentos sociais populares.

Visando contribuir com as pesquisas em educação, o objetivo desse artigo é reunir elementos teórico-metodológicos presentes na obra de Edward P. Thompson. Após contextualizar sua produção teórica, articulada à sua militância política, serão abordadas, especificamente, suas análises acerca da história como processo, do "fazer-se" da classe trabalhadora e da consciência de classe no contexto da Revolução Industrial, na Inglaterra, em que estavam em disputa dois modos de vida. Explicitamos suas considerações sobre experiência e educação, destacando o autodidatismo e as aprendizagens coletivas cotidianas como elementos da formação política da classe operária. Considerando a dialética passado, presente e futuro na análise dos desafios do mundo atual, sintetizamos as contribuições teórico-metodológicas da obra de Edward. P. Thompson, trazendo antigas e novas perguntas para a pesquisa histórica, sociológica e educacional. 


\section{Paixão e intelecto: a relação entre militância política e produção acadêmica}

Mais conhecido entre historiadores, Edward P. Thompson tem ocupado um lugar de destaque nas pesquisas em educação. Isso se deve à originalidade e densidade de sua obra, bem como à sua trajetória e militância política.

Thompson nasceu em uma família de missionários metodistas, em Oxford, no ano de 1924. Tudo indica que sua militância política teve origem no interior da família, especialmente pela influência de seu irmão mais velho, Frank Thompson, que o precedeu no Partido Comunista da Grã-Bretanha (PCGB). Durante a Segunda Guerra Mundial, seguindo o caminho do irmão, Edward serviu nas frentes de luta contra o nazi-fascismo, na África e na Itália. Após a guerra, completou o seu curso de história na Corpus Christi College, Cambridge, em 1946, onde se juntou ao Partido Comunista.

Em 1948, Thompson tornou-se professor de história na Universidade de Leeds e durante 17 anos trabalhou com educação de adultos em cursos "extramuros" dirigidos a sindicalistas e demais trabalhadores. Criou a Associação Educacional de Trabalhadores, cujo objetivo era socializar e defender os valores da cultura operária, contrapondo-se aos valores da burguesia. Mais tarde, atuou no Centro de Estudos de História Social da Universidade de Warwick onde, junto com os estudantes, dedicou-se ao estudo de questões do século XVIII relativas ao crime e à lei, o que resultou no livro Senhores e caçadores (1987). Apesar de sua crescente influência, Thompson manteve uma relação ambivalente com o mundo acadêmico; considerava-se um estranho acadêmico e crítico do professorado.

Thompson, Eric Hobsbawm, Christopher Hill, George Rude, Maurice Dobb, entre outros, juntaram-se para formar o Grupo de Historiadores do Partido Comunista da GrãBretanha, o qual se tornou um dos principais núcleos de elaboração teórica acerca do marxismo. Além de Raymond Willians, que não era historiador, estava presente nesse grupo a historiadora Dorothy Thompson, companheira e camarada que acompanhou Thompson até a sua morte, em 1993. Tendo como referência o materialismo histórico, os membros do grupo fundaram, em 1952, o jornal Passado e Presente, pioneiro no estudo da história da classe trabalhadora inglesa.

Assim como Hobsbawm e Rude, Edward P. Thompson elaborou a partir da década de 1950 estudos em que resgata a história das classes trabalhadoras inglesas, abordando as experiências e culturas das pessoas não apenas como simples atos de ideias, mas também como sentimentos, valores e consciência.

Desiludidos com os acontecimentos na União Soviética e a invasão da Hungria, com o ocultamento dos crimes de Stalin e censura do jornal The Reasoner do PCGB, Thompson e outros marxistas abandonaram a agremiação partidária, em 1956. Mesmo afastado do Partido, manteve sua militância política; em 1957, ajudou a formar a Campanha pelo Desarmamento Nuclear (CND) e, com John Saville, começou a publicar The New Reasoner, que deu origem ao movimento político que ficou conhecido como Nova Esquerda.

A trajetória de vida de Thompson, para além dos muros acadêmicos, lhe proporcionou elementos suficientes para pensar a realidade social de forma menos rígida e estruturalista. Ele mesmo lembrou a Louis Althusser que conhecimentos se formaram e se formam fora dos procedimentos acadêmicos e dos recintos da universidade. Como professor de adultos em aulas para trabalhadores e sindicalistas, como militante do Partido Comunista e do Movimento Anti-Nuclear na Europa, logo aprendeu que "a experiência não espera discretamente, fora de seus gabinetes, o momento em que o discurso da 
demonstração convocará a sua presença. A experiência entra sem bater à porta e anuncia mortes, crises de subsistência, guerra de trincheira, desemprego, inflação, genocídio" (1981, p.17). Frente a estas experiências, Thompson indica que velhos sistemas conceituais podem desmoronar e novas problemáticas podem insistir em impor sua presença.

Ao retomar a ideia marxista da classe como sujeito, como categoria histórica, ampliou seu significado, enquanto relação. Segundo a análise de Wood (2003), para Thompson não há oposição entre estrutura e processo, há processos estruturados. "Classe é um fenômeno visível apenas no processo" (Idem, p. 72). De acordo com essa autora, o método de investigação de Thompson torna possível o reconhecimento do papel ativo da classe trabalhadora, com sua cultura e seus valores, na sua própria "formação". Sua preocupação é tornar a classe visível na história, não apenas como construto teórico.

Por dedicar-se ao estudo das tradições, dos costumes e modos de vida, Thompson tem sido interpretado, de forma equivocada, como um historiador culturalista ${ }^{4}$. Entretanto, ao contrário de compreender a cultura no seu sentido abstrato, descolada da materialidade histórica, o autor privilegia o estudo empírico, atenta-se para os sujeitos que vivenciam os processos culturais, articulando-os com o movimento real da sociedade, sem perder de vista a análise mais ampla de base marxista.

Existem diversos elementos teórico-metodológicos presentes nas obras de Thompson que contribuem para o entendimento do sentido histórico das atuais experiências coletivas de trabalhadores, suas raízes históricas e suas possibilidades futuras, considerando a dialética passado, presente e futuro. As contradições e ambivalências das experiências históricas; as condições objetivas e subjetivas das situações reais; o estudo do contexto social, dos costumes, da relação com o tempo, da disciplina no trabalho, das tradições das experiências e da cultura que nelas emergem são questões presentes no estudo da formação da classe operária inglesa e, também, elementos preciosos para pensar os movimentos populares na atualidade Seus principais escritos, publicados no Brasil, são A miséria da teoria: ou um planetário de erros (1981); A formação da classe operária inglesa, em três volumes (1987); Senhores e Caçadores (1987); Os românticos. A Inglaterra na era revolucionária (2002); Costumes em comum. Estudos sobre a cultura popular tradicional (2008); e A peculiaridade dos ingleses e outros artigos, organizado por Negro e Silva (2001).

Para Eric Hobsbawm (2001), a obra de Thompson aliou paixão e intelecto.

\section{Experiência e consciência: a classe como formação econômica e cultural}

A consciência é definida pelos homens ao viver sua própria história e, ao final, é a única definição. (Thompson, 1984, p. 34)

A partir da análise que Thompson faz na sua obra A formação da classe operária inglesa, referente ao período histórico entre 1790 e 1830, contexto que fez emergir uma nova classe organizada, apreendemos sua concepção de classe, de consciência e de luta de classe, bem como de experiência. Observamos, assim, que as categorias emergem das relações sociais, são históricas e representam as situações reais no campo do pensamento.

Thompson iniciou no primeiro volume da obra acima citada, em 1790, a descrever a primeira reunião de uma pequena Sociedade de Correspondência de inspiração radicalpopular e que em menos de 30 anos se desdobra em outras, que se transformam em 
organizações propriamente operárias, criando condições, já em 1819, para uma revolução constitucional na Inglaterra.

No último volume, A força dos trabalhadores, Thompson nos mostra que diante da censura e da repressão das classes dominantes inglesas, os trabalhadores teceram sua experiência na mais profunda clandestinidade, para aparecer finalmente à luz do dia ensaiando as manifestações de uma revolução democrática. $\mathrm{O}$ autor recolhe a história do radicalismo plebeu, levando-a por meio do luddismo ${ }^{5}$, até a época heróica no final das Guerras Napoleônicas. Discute alguns aspectos da teoria política e da consciência de classe nos anos 1820 a 1830 . Vai percorrer a tradição clandestina, abordando o movimento luddista, o sindicalismo ilegal, seu contexto industrial e seu sentido político e revolucionário, questionando as fontes históricas.

Na primeira metade do séc. XIX, o descontentamento social no Reino Unido deu origem ao Cartismo, o primeiro movimento revolucionário da classe proletária, sustentado pela agitação radical de trabalhadores de pequenas oficinas. Foi o movimento político reformista de trabalhadores britânicos que ocorreu entre 1836 e 1850 e cujo programa estava na Carta do Povo, redigida por William Lovetti. Reivindicava sufrágio universal, direitos eleitorais homogêneos, voto secreto, eleição parlamentar anual, elegibilidade dos não-proprietários e subsídios para os deputados. Tais reivindicações podem parecer insignificantes ou pouco revolucionárias na atualidade, entretanto a luta pelo direito ao voto implicava uma nova forma dos trabalhadores tentarem alcançar o controle social sobre suas condições de vida e de trabalho.

Por volta de 1832, havia instituições da classe operária solidamente fundadas e autoconscientes - sindicatos, sociedades de auxílio mútuo, movimentos religiosos e educativos, organizações políticas, periódicos - além das tradições intelectuais, dos padrões comunitários e da estrutura da sensibilidade da classe operária.

Da revolta dos trabalhadores na destruição de máquinas, assistimos nos anos de 1830, aos homens lutarem, não contra a máquina, "mas contra as relações exploradoras e opressivas intrínsecas ao capitalismo industrial" (Thompson, 1987, v. 3, p. 440). Nesse momento, é possível falar de uma nova forma de consciência dos trabalhadores em relação aos seus interesses e à sua situação enquanto classe, que se refletem na identidade de interesses entre trabalhadores das mais diversas profissões e níveis de realização, de um lado, e na identidade dos interesses da classe operária, de outro, expressos em muitas formas institucionais e no sindicalismo de 1830-34.

Para explorar a experiência da qual surgiu a expressão cultural e política da consciência da classe operária, o autor analisa a mudança de vida de três grupos de trabalhadores: rurais, artesãos e tecelões; o padrão de vida da população; as compulsões internas do modo de vida industrial e a influência do Metodismo sobre elas; e alguns elementos das comunidades da nova classe operária.

$\mathrm{Na}$ agricultura, os anos de 1760 e 1820 foram a época de intensificação dos cercamentos, em que os direitos a uso da terra comunal foram perdidos. Nas indústrias domésticas, a partir de 1800, os pequenos mestres foram cedendo lugar aos grandes empregadores e a maioria dos tecelões e dos fabricantes de pregos tornaram-se trabalhadores assalariados externos. Nas tecelagens e em várias áreas mineradoras, esses são os anos de trabalho de crianças e, clandestinamente, de mulheres.

"Todo processo de industrialização é necessariamente doloroso, porque envolve a erosão de padrões de vida tradicionais" (Thompson, 1987, v. 2, p. 342). Entre 1780 e 1840, mesmo tendo havido aumento significativo no produto nacional, a Revolução Industrial provocou o empobrecimento da população, modificando sobremaneira o seu modo de ser. 
Sobre a dieta popular, Thompson conta que a substituição do pão e da farinha de aveia pela batata era considerada degradação; mesmo quando se encontrava a beira da falência, o trabalhador rural do sul recusava-se a abandonar a dieta de pão e queijo. O número excessivo de horas de trabalho, acompanhada de uma alimentação inadequada, requeria o maior consumo de álcool e de chá, como estimulantes.

As mudanças econômicas produziram mudanças na cultura alimentar, gerando "durante aproximadamente cinquenta anos uma autêntica luta de classes" (Thompson, 1987, v.2, p. 180), o que pode ser evidenciado nos motins da fome, considerados como expressão da economia moral das multidões. Desses motins, caracterizados como um movimento da pequena indústria manufatureira, participavam operários de pequenas empresas, trabalhadores em domicilio, trabalhadores de lã e tecelagem e mineiros. Lutavam contra as formas de taxação do licor, sidra, cerveja e gim, contra o cercamento dos terrenos comunais, contra o recrutamento forçado da Marinha, contra os pedágios de passagem e a construção de novas estradas com novos pedágios.

O empobrecimento advindo da Revolução Industrial repercutiu nas péssimas condições de moradia, na inserção das crianças no trabalho fabril, nas longas jornadas de trabalho, no mau cheiro do lixo industrial e deterioração do ambiente urbano etc. Entre as perdas sofridas na mudança de um modo de vida para o outro, cita:

[...] para o trabalhador rural, a perda dos direitos comunais e dos resquícios de democracia nas aldeias; para o artesão, a perda de seu status; para o tecelão, a perda do seu meio de vida e da sua independência; para a criança, o fim do trabalho e do lazer domésticos; para os diversos grupos de trabalhadores cujos salários reais aumentaram, a perda da segurança e do tempo livre, ao lado da deterioração das condições ambientais urbanas. (Thompson, 1987, v. 2, p. 345)

Em síntese, o que ocorreu foi uma violência da classe capitalista "contra a natureza humana" (Ibid, p.346). Thompson observa a criação de um tipo novo de trabalhador e de homem, enfim, a forma como a revolução muda as condições e as exigências da formação humana. O novo modo de vida significa "estar à disposição deles", colocando fim à autonomia no trabalho, à produção para a subsistência, bem como ao controle sobre o processo de produção. Há uma separação entre os locais de vida e os locais de trabalho; o tempo de trabalho e o tempo livre.

O empreendimento em grande escala, o sistema fabril com sua nova disciplina, as comunidades fabris - tudo contribuiu para a transparência do processo de exploração e para a coesão social e cultural de explorado. O povo foi submetido à intensificação de duas formas intoleráveis de relação: a exploração econômica e a opressão política.

Contestando as teses históricas, Thompson vai mostrar que a classe trabalhadora inglesa não foi gerada espontaneamente pelo sistema fabril, pela máquina a vapor ou por alguma força exterior - a Revolução Industrial ou a Revolução Francesa. "O fazer-se da classe operária é um fato tanto da história política e cultural quanto da econômica." (Thompson, 1987, v. 2, p. 17). A classe operária formou a si própria tanto quanto foi formada.

Para o autor, a classe é uma formação tanto cultural como econômica, é uma relação social, é fruto de experiências comuns, determinadas, em grande medida, pelas relações de produção. Enfatiza que, ao fazer generalizações apressadas e ocultar os conflitos sociais, a "história vista de cima" pode reduzir a história à história dos dominadores. Por isso, enfatiza a dimensão cultural da formação da classe trabalhadora 
inglesa reconstruindo aspectos da vida comunitária dos trabalhadores pré-industriais e o modo de vida da plebe, que está em vias de se constituir como classe operária.

Embora reconheça a importância da antropologia para a compreensão da cultura popular, critica os antropólogos pela utilização do conceito de cultura destituído da vida real, descontextualizado da materialidade do processo histórico Para Thompson, a cultura só pode ser considerada no contexto amplo do desenvolvimento histórico, atada aos conceitos de sociedade e economia. Como processo social constitutivo que cria 'modos de vida' específicos e diferenciados, a cultura está visceralmente vinculada com a vida material. Não podendo ser compreendida dentro de um quadro de imposição hegemônica da dominação de classe, a cultura popular constitui-se como campo de resistência e luta contra a exploração e, ao mesmo tempo, como campo de disputa de interesses conflitantes.

Como formação econômica e cultural, a classe é um fenômeno histórico, algo que ocorre efetivamente nas relações humanas, não de uma forma determinada, mas como uma capacidade de percepção e articulação de interesses de alguns indivíduos contra outros, cujos interesses diferem dos seus. E a "consciência de classe é a forma como essas experiências são tratadas em termos culturais: encarnadas em tradições, sistemas de valores, ideias e formas institucionais." (Thompson, 1987, v.1, p. 10).

Nesta direção, a noção de classes é inseparável da noção de luta de classes.

Na realidade, luta de classes é um conceito prévio assim como muito mais universal. Para expressá-la claramente as classes não existem como entidades separadas, que olham ao redor, encontram uma classe inimiga e começam logo a lutar. Pelo contrário, as pessoas (gentes) encontram-se em uma sociedade estruturada em modos determinados [...], experimentam a exploração [...], identificam pontos de interesse antagônico, começam a lutar por essas questões e no processo de luta se descobrem como classe, e chegam a conhecer este descobrimento como consciência de classe. A classe e a consciência de classe são sempre as últimas, não as primeiras, fases do processo real histórico. (Thompson, 1984, p. 37)

Thompson considera as classes como um processo em formação, um "fazer-se", constituída e constituinte da luta, o que implica considerar a experiência humana, a qual é gerada na vida material e estruturada em termos de classe.

Pela experiência os homens se tornam sujeitos, experimentam situações e relações produtivas como necessidades e interesses, como antagonismos. Eles tratam essa experiência em sua consciência e cultura e não apenas a introjetam. Ela não tem um caráter só acumulativo. Ela é fundamentalmente qualitativa. (Thompson, 1981, p. 99)

A experiência "compreende a resposta mental e emocional, seja de um indivíduo ou de um grupo social, a muitos acontecimentos inter-relacionados ou a muitas repetições do mesmo tipo de acontecimento" (Thompson, 1981, p.15). Portanto, apreender a experiência implica apreender o processo e o contexto social que a engendra.

Há uma relação permanente entre a matéria e o pensamento, um implica o outro, o que pressupõe o diálogo entre o ser social e a consciência social. "A experiência surge espontaneamente no ser social, mas não surge sem pensamento. Surge porque homens e mulheres (e não apenas filósofos) são racionais, e refletem sobre o que acontece a eles e ao seu mundo. [...] assim como o ser é pensado, também o pensamento é vivido" (Thompson, 
1981, p.16 e 17). A experiência é o vivido, são os acontecimentos, as ações e o sentido a elas atribuído.

A experiência, segundo a análise de Wood (2003), informa que as estruturas objetivas geram efeitos sobre a vida das pessoas. É por isso que temos classes e não apenas relações de produção. A experiência comum é vivida de relações de produção, onde toma forma a consciência social e com ela "a disposição de agir como classe". (Idem, p. 89)

Como temos visto, Thompson aborda a história como processo, o que implica em articular o presente, o passado e o futuro. Reacende as experiências passadas em articulação com as atuais. Analisa, por exemplo, a cultura radical marcada pelo autodidatismo, pelas sociedades de leitura, pela alfabetização, pela imprensa radical, pelo teatro, cartum popular e político. Segundo o autor, a década de 1820 parece calma, mas foram os anos de luta pela liberdade de imprensa, do aumento da força sindical e da revogação das leis de associação, do crescimento do livre pensamento, da experiência cooperativa e da teoria owenista. No final da década, Thompson observa uma nova forma de consciência dos trabalhadores em relação aos seus interesses e à sua situação enquanto classe.

Investiga um período adequado de mudanças sociais e não acontecimentos, observando padrões em suas relações, suas ideias e instituições. Pode parecer que este é um registro de frustrações e fracassos, mas a experiência apresenta um outro lado muito mais positivo, visto que muitas tradições se originam desses anos. Há a tradição intelectual, a tradição do deísmo e do livre pensamento, a tradição dos unitaristas avançados e cristãos livre-pensadores, dos comerciantes e artesãos sóbrios, com orientação constitucionalista. "Estas tradições estão encarnadas não só em ideias, mas em pessoas." (Thompson, 1981, v.1, p. 198).

Por entender que a classe é uma formação tanto cultural como econômica, Thompson adverte que não devemos fazer generalizações a partir da experiência inglesa. Isso significa que a compreensão da formação da classe operária na Irlanda, na Escócia ou em qualquer outro país ou nação requer uma reconstrução histórica que considere as particularidades de cada espaço/tempo, como as formas como se materializam no tecido social as questões de religiosidade, dos laços sindicais, da cultura popular, da composição do campesinato etc. Em outras palavras, sem desconsiderar as determinações gerais do modo de produção capitalista, cabe ao pesquisador perceber as formas peculiares como os sujeitos sociais participam, de forma ativa, nos processos de produção da existência.

\section{Educação e experiência: as determinações da ação humana}

A experiência não espera discretamente, fora de seus gabinetes, o momento em que o discurso da demonstração convocará a sua presença. A experiência entra sem bater à porta e anuncia mortes, crises de subsistência, guerra de trincheira, desemprego, inflação, genocídio. (Thompson, 1981, p.17)

Em seus estudos empíricos, Thompson evidencia que os trabalhadores não foram vítimas passivas das mudanças ocorridas no século XVIII. Elenca diversos elementos que corroboraram para o crescimento da consciência da classe operária inglesa, num contexto em que dois modos de vida estavam em disputa. Como prefere Raymond Willians, o que caracterizou a vida na Inglaterra nesse momento histórico foi a "coexistência de ideias 
alternativas sobre a natureza das relações sociais" (apud Thompson, v. 2, p. 316). No processo de transição para o capitalismo, de um lado, encontram-se os instrumentos disciplinares das fábricas, das escolas dominicais, da igreja etc., para impor a ordem moral necessária para a vitória da indústria capitalista, destruindo o equilíbrio entre vida urbana e vida no campo. De outro lado, enriquecidas pelo radicalismo político e pelo owenismo, constata-se o crescimento do número de rituais de reciprocidade entre os trabalhadores, reforçando os valores e práticas coletivistas, propagadas na teoria política, nos cerimoniais dos sindicatos e associações de ofício. No processo de luta, os trabalhadores:

[...] também experimentam sua experiência como sentimento e lidam com esses sentimentos na cultura, como normas, como obrigações familiares e de parentesco, e reciprocidades, como valores ou (através de formas mais elaboradas) na arte ou nas convicções religiosas. Essa metade da cultura (e é uma metade completa) pode ser descrita como consciência afetiva e moral. (Thompson, 1981, p.193)

Um dos capítulos do volume $3 \mathrm{~d} A$ formação da classe operária inglesa (1987) intitula-se Consciência de Classe, nele Thompson focaliza as dimensões educativas, os movimentos sociais populares, bem como o autodidatismo como ferramenta de formação política. Embora a instrução de grande parte do povo inglês se restringisse a ler, escrever e contar, isso não significou atrofia intelectual, ao contrário. As técnicas elementares de alfabetização propiciavam a aprendizagem individualmente ou em grupos, reunindo artesãos, diaristas, lojistas, mestres-escolas, sapateiros, alfaiates etc. Outros recursos propiciavam a leitura do mundo: era comum frequentar bares onde se podia escutar a leitura, em voz alta, de um panfleto ou jornal; escutar um sermão ou ouvir o discurso de um orador radical. Além das noticias de jornais que eram socializadas nas ferrarias, barbearias e tabernas, podia-se obter informações por meio dos vendedores de cartazes e dos cantores de rua. Principalmente nos momentos de efervescência política, os alfabetizados liam os periódicos para os demais companheiros de trabalho. As publicações do Parlamento também se tornavam um material pedagógico importante. "Um sapateiro que aprendera a ler pelo Antigo Testamento, ia se aperfeiçoar com a Idade da razão; um mestre-escola, cuja instrução não o levara muito além das meritórias homílias religiosas, tentaria Voltaire, Gibbon, Ricardo" (Thompson, 1987, v. 3, p. 304). Eram diversas as possibilidades de apreensão da realidade humano-social.

Constando ser "termo ausente" na teoria de Althusser, Thompson (1981) entende que a experiência humana tem papel central no processo de formação social. Dizer que o ser social determina a consciência social, significa dizer que as determinações não se restringem às de base econômica, propriamente ditas, mas que há um entrelaçamento entre vida material, vida social e vida cultural, mediadas pela experiência, pela ação humana.

Para o autor, as pessoas não apenas reproduzem experiências e as introjetam em sua consciência; as experiências vividas produzem, qualitativamente:

[...] mudanças no ser social que dão origem à experiência modificada; essa experiência é determinante, no sentido de que exerce pressões sobre a consciência social existente, propõe novas questões e proporciona grande parte do material sobre o qual se desenvolvem os exercícios intelectuais mais elaborados. (Thompson, 1981, p. 16) 
A experiência é uma categoria com sentido histórico, capaz de apreender no campo do pensamento a síntese dos elementos da vida concreta, real, os quais dizem respeito à objetividade e à subjetividade, ao individual e ao coletivo, ao universal e ao particular. Torna-se o objeto empírico para análise dos costumes, tradições, sistema de valores. É o material sobre o qual o historiador, o sociólogo, o educador e outros estudiosos devem se debruçar para a compreensão da totalidade social. É uma categoria que propicia o entendimento das particularidades e singularidades dos processos de produção da vida social. No que diz respeito à educação escolar, acredita que:

A experiência modifica, às vezes de maneira sutil e às vezes mais radicalmente, todo o processo educacional; influencia os métodos de ensino, a seleção e o aperfeiçoamento dos mestres e o currículo, podendo até mesmo revelar pontos fracos ou omissões nas disciplinas acadêmicas tradicionais e levar à elaboração de novas áreas de estudo. (Thompson, 2002, p. 13)

Com base nesse entendimento, Thompson vai mostrar como a educação se distanciou da experiência. A educação veio a se apresentar não apenas como uma baliza na direção de um universo mental novo e mais amplo, mas também como uma baliza para fora do universo da experiência. Tendo em vista o desejo de dominar e de moldar o desenvolvimento intelectual e cultural do povo, o que conduz ao medo da cultura popular autêntica, o resultado foi a oposição entre educação e experiência.

De acordo com Thompson (2002, p. 45), "as universidades precisam do contato de diferentes mundos de experiência, no qual ideias são trazidas para prova da vida", há necessidade da crítica dos que estão de fora. Ou ainda, o "departamento extramuros da universidade" deveria ser um lugar importante para essa dialética: "uma porta de saída para o conhecimento e as competências, uma porta de entrada para a experiência e a crítica." Daí a necessidade da busca de equilíbrio entre o rigor intelectual e o respeito pela experiência, visto que a universidade é o espaço para ensinar, mas também para aprender.

A produção e a socialização do conhecimento nas universidades guardam uma distância descomunal com as experiências da classe trabalhadora, com as associações coletivas e movimentos sociais organizados. A interlocução se faz, predominantemente, com setores organizados do capital, para atender e prestar serviços de acordo com seus interesses. Tal situação, além de manter a classe trabalhadora a margem da universidade, traz prejuízos à própria ciência e ao ensino, desequilibrando as diversas áreas do conhecimento em termos de investimentos e base de desenvolvimento. Como consequência, a formação dos jovens tem como foco o mercado, distanciada de uma educação mais ampla articulada com a experiência humana.

A experiência a qual Thompson se refere não é sinônimo de empirismo ou pragmatismo. A categoria experiência também não significa simplesmente experenciar algo e, portanto, não pode ser tomada em si. Marx (1982) nos ajuda na compreensão, ao observar a capacidade que têm as categorias de apreender a síntese social. Considera-as como relações sociais, com caráter histórico e transitório das formas de produção numa época determinada. "Os homens, que produzem as relações sociais em conformidade com a sua produtividade material, produzem também as ideias, as categorias, isto é, as expressões abstratas ideais [idéelles] dessas mesmas relações sociais. Assim, as categorias são tão pouco eternas quanto as relações que exprimem." (Marx, 1982, p. 551). A apreensão teórica das relações sociais não se dá por meio de categorias estáticas, pelo fato 
da realidade estar em constante movimento, sendo este contraditório. Ao refletir sobre o sentido da experiência humana, estamos refletindo sobre a forma de apreendê-la.

Os ideólogos da Escola Nova fazem a crítica à educação tradicional, especialmente no que se refere à negação do mundo da experiência. Defendem uma escola ativa, dinâmica, centrada no aluno e buscam trazer para a escola o mundo exterior, a experiência. Dewey (1979), por exemplo, com base nos pressupostos do pragmatismo, experimentalismo, princípio da continuidade, verdade como práxis e escola nova, desenvolve ideais pedagógicos e filosóficos adequados a uma sociedade técnico-industrial. A escola é vista como ambiente especial, em que o meio é preparado para influir na direção moral e mental dos estudantes, um ambiente purificado para a ação. Observa-se que o ensino nesta perspectiva busca trazer a experiência para o ambiente escolar de forma artificial, individual e parcial. Não se trata da experiência humana em sua totalidade e não se trata de uma escola em real articulação com a vida e o trabalho.

A experiência de que trata Thompson também não pode ser confundida com o tão propalado lema do "aprendizado ao longo da vida", com o aprender pela experiência, o aprender fazendo presente na época do Artesanato (Rugiu, 1998) ou o aprender a aprender ${ }^{6}$. Tais lemas sustentavam-se num contexto histórico em que a produção da vida se dava de forma artesanal, individual, dependendo das mãos habilidosas dos mestres artesãos. A educação, nesse período, em consonância com o trabalho, também era individual e dependia da observação e da experiência prática do aprendiz. Diferente da sociedade moderna industrial, em que o trabalho é social e universal, exigindo uma escola também universal, com conteúdos gerais.

Por fim, a experiência é histórica e, portanto, implica em considerar o passado, o presente e o futuro. Temos como pressuposto que a realidade presente não é a única realidade, sendo assim, não é o único critério de educação. O verdadeiro critério é a realidade futura. Suchodolski, na obra A pedagogia e as grandes correntes filosóficas (2002), apresenta um caminho que permite resolver a antinomia do pensamento pedagógico moderno, a "educação virada para o futuro e a perspectiva de um sistema social à escala humana". Nesta concepção, o presente deve ser submetido à crítica.

As análises de Thompson nos levam a refletir sobre quais experiências socializam na atualidade. Para muitos, já não é o trabalho o elemento central do processo de socialização, mas a comunicação ou a linguagem ${ }^{7}$, os movimentos sociais ${ }^{8}$, o lazer $^{9}$ e outros. Apreendem a realidade na sua aparência e enquanto experiência particular ou pontual, falseando ou limitando a possibilidade de apreender o conjunto da realidade e suas contradições, as transformações na indústria, no trabalho e nos trabalhadores.

Thompson refere-se à experiência humana como experiência de classe, que se constitui materialmente, com base nas relações econômicas, sociais e culturais. Para ele, a experiência de classe é determinada, em grande medida, pelas relações de produção em que os homens nasceram - ou entraram involuntariamente (1987, p.10). Grifamos a expressão em grande medida para ressaltar que o autor não absolutiza as condições objetivas como determinantes na ação dos trabalhadores. A formação da classe resulta do cruzamento das determinações com a auto-atividade, por isso, "se a experiência aparece como determinada, o mesmo não ocorre com a consciência de classe" (Ibid). Caso contrário, a classe trabalhadora não seria o principal agente de transformação da realidade humano-social. Tampouco poderíamos afirmar que a libertação da classe trabalhadora será obra dos próprios trabalhadores, conforme preconiza Marx no preâmbulo do manifesto de lançamento da Associação Internacional do Trabalho - AIT, criada em 1864. 


\section{Contribuições de Edward P. Thompson: antigas e novas perguntas de pesquisa}

A teoria está sempre recaindo numa teoria ulterior. Ao recusar a investigação empírica, a mente está para sempre confinada aos limites da mente. Não pode caminhar do lado de fora. É imobilizada pela cãibra teórica e a dor só é suportável se não movimentar seus membros. (Thompson, 1981, p.185)

Os desafios do mundo atual, marcado pelo que Milton Santos chama de globalização perversa (2009), têm como ápice o processo de internacionalização do mundo capitalista, sustentado pela dupla tirania: a do dinheiro e a da informação. O que exige de nós compreender o que significa tal momento histórico, o que há de novo, o que é reprodução e, especialmente, como enfrentar tal situação, ou nas palavras de Santos, como projetar o mundo como pode ser. Para compreender o presente com radicalidade, há que se ampliar a nossa análise, em termos temporais e espaciais. Num mundo plenamente internacionalizado, que se reproduz universalmente e socialmente, as soluções são menos locais e pontuais, as quais exigem uma análise do presente pautada no passado e com projeção para o futuro.

$\mathrm{Na}$ introdução do livro Costumes em Comum (2002), Thompson enfatiza que devemos colocar em dúvida a ideia do "homem econômico" como a nova natureza humana criada pelo capitalismo. Adverte que, se por um lado, "nunca retornaremos à natureza humana pré-capitalista", de outro, "lembrar como eram os seus códigos, expectativas e necessidades alternativas pode renovar nossa percepção sobre a gama de possibilidades implícitas no ser humano" (Thompson, 2002, p. 23). Mas, de que maneira Edward Palmer Thompson pode nos ajudar a compreender a complexidade das relações sociais, nesse momento histórico em que a questão das classes sociais permanece viva e atual, ainda que recorrentemente negada por pesquisadores liberais (ou neoliberais; ou pós-modernos)?

Com a crise estrutural do trabalho assalariado, como expressão da crise do capital, bem como a mudança das formas de regulação do capital, o mundo do trabalho ganhou novas configurações, modificando sobremaneira a forma de ser da classe trabalhadora. Submetendo-se ao trabalho temporário, sazonal e em tempo parcial, homens e mulheres passaram a buscar o trabalho por conta própria, como única ou como fonte complementar de renda, alternando seu status ora de trabalhador/a assalariado/a, ora "patrão de si mesmo". Forjando uma classe trabalhadora diversificada, heterogênea e multifacetada, a reestruturação produtiva e a flexibilização das relações entre capital e trabalho repercutiram na precarização da própria vida. Ainda que diversa, variada, dividida com base na ocupação, habilidade, gênero, ideologia etc., a classe trabalhadora compreende uma vasta maioria da população que, para viver, depende da venda de sua força de trabalho. Não por acaso, no contexto da mundialização do capital, a contraposição e oposição entre as classes sociais tem se manifestado em todas as dimensões da vida de forma muitas vezes violenta. Se, como Thompson, podemos afirmar que toda luta de classe é uma luta de interesses e valores em torno de concepções de vida, é importante buscar apreender outras formas de produzir, comercializar e consumir que perduram no atual tempo histórico. Nesse sentido, é emblemático o depoimento de Abel Palácios, morador de uma comunidade indígena em Salta (Argentina), a respeito do cooperativismo popular:

Una cooperativa indígena es, de por sí, una cooperativa sin papeles, claro está, pero funciona como cooperativa. Una comunidad no lleva el nombre 
de 'cooperativa', pero tenemos algo parecido que llamamos minga. Cuando un hermano de la comunidad necesita hacer un trabajo en su casa o en su producción, todos los demás le van a ayudar; cuando otro hermano necesita algo, todos les ayudan; esto es una forma de cooperativismo, pero no con ese nombre; nosotros le decimos minga. Se forma una minga para arreglar los caminos, hacer un puente para que en el verano la maestra pueda llegar a la escuelita. Para todo eso la gente se junta para trabajar de una forma muy unificada. (In: Giarracca y Massuh, 2008, p. 145)

Ao longo da história do capitalismo, o modo de vida foi se conformando, trazendo dentro de si, ainda que de forma periférica e submetida aos desígnios do modo de produção dominante, elementos de culturas específicas de grupos sociais que, historicamente, pautaram-se em outros paradigmas econômicos e culturais. No entanto, no contexto da globalização de bens materiais e simbólicos, incorpora-se tudo aquilo que pode se tornar útil à valorização do capital. Se, de um lado, o reconhecimento da diversidade de gênero, de raça e etnia, orientação sexual etc. tornou-se palavra de ordem dos movimentos sociais que reúnem sujeitos e grupos sociais que, historicamente, foram tratados como inferiores ou marginais, de outro, como jargões, o "respeito à diversidade cultural" e à promoção da "inclusão social", insistentemente veiculados pelos meios de comunicação de massa e incorporadas às políticas educacionais, assegura o preceito da flexibilização do mercado, de maneira a ampliar a oferta de produtos e serviços aos setores sociais que, por serem potenciais consumidores, passam a ser considerados como "cidadãos".

Numa perspectiva pós-moderna ${ }^{10}$, a apologia à "diversidade" em detrimento da categoria classe social, pode torná-la invisível aos olhos dos pesquisadores. Para o historiador marxista inglês E. P. Thompson (1987, v.1, p. 11), "se detemos a história num determinado ponto, não há classes, mas simplesmente uma multidão de indivíduos com um amontoado de experiências". Se "a classe é definida pelos homens enquanto vivem sua própria história" (Ibid), cabe-nos examinar as formas pelas quais homens e mulheres transitam e se (re)posicionam frente às contradições do capital, "observando padrões em suas relações, suas ideias e instituições" (Ibid). Por não se tratar de um conceito estático, a análise da classe trabalhadora hoje, na sua complexidade, pressupõe a análise de seu (re)fazer-se no processo histórico. Que elementos de ordem econômica, política e cultural podem contribuir no entendimento do modo de ser dos trabalhadores e trabalhadoras?

A partir do estudo de Thompson sobre a classe trabalhadora na Inglaterra, podemos inferir que, no atual contexto do regime de acumulação flexível, em que as classes sociais podem parecer ofuscadas, torna-se necessário proceder a reconstrução histórica das experiências coletivas dos trabalhadores, no âmbito dos sindicatos, associações e outros movimentos sociais organizados. Quais os significados dos movimentos por ocupação de terras, moradias e fábricas? No campo e na cidade, como os trabalhadores assalariados, trabalhadores por conta própria e trabalhadores associados constroem sua identidade de classe? E quanto àqueles que estão vagando pelas ruas dos grandes centros urbanos? Frente à precariedade das condições de trabalho e à árdua luta para garantir a reprodução da vida, poderíamos considerar como economia moral das multidões as estratégias de trabalho e de sobrevivência de crianças, jovens e adultos que perambulam pela cidade? Em que medida seus interesses e expectativas se configuram como antagônicos ao grupo dos compradores de força de trabalho? Como se organizam? Que experiências associativas estão vivendo? Parafraseando Thompson, se estamos interessados na transformação histórica, temos que atentar para as minorias, "cuja consciência social pode ser atualmente considerada 
"subpolítica" e que, certamente, são pessoas que "deixam pouco registro de seu pensamento" (Thompson, 1987, v. 1, p.57).

Que concepções de mundo carrega o grande contingente de homens e mulheres que vivem da venda da força de trabalho ou que, no contexto do desemprego crescente, não encontram lugar no mercado de trabalho? Se a classe social, que se constitui pela posição dos trabalhadores na produção e configura-se, ainda, como um fenômeno histórico que dá sentido a uma série de acontecimentos aparentemente díspares e desconectados, cabe-nos perceber em que medida as experiências comuns de trabalhadores e trabalhadoras do campo e da cidade são manifestações da luta de classes. Se classe e consciência de classe resultam de experiências comuns partilhadas, que se constituem e constituem o próprio "fazer-se", cabe-nos apreender as mediações, a maneira pelas quais essas experiências são tratadas culturalmente, expressando-se nos costumes, tradições, símbolos e sistemas de valores.

Thompson (2002) sugere que na esfera sociopolítica, o modo de viver, pensar, agir, os hábitos, os costumes e as tradições dos sujeitos individuais e coletivos são elementos de resistência e criação de uma nova cultura ou de manutenção do modo de vida existente. Se os costumes podem significar um importante papel nas rotinas de trabalho, de certa forma podem expressar também os saberes/conhecimentos das experiências produzidos pelos trabalhadores nos espaços de trabalho. Certamente as formas populares de fazer economia guardam elementos da 'cultura costumeira' das classes trabalhadoras. E quanto aos movimentos sociais populares de resistência ao modo de vida imposto pelo modo de produção capitalista? O que podemos apreender das culturas comunitárias milenares, como as andinas, por exemplo, que se pautam na relação de reciprocidade entre seres humanos e natureza e os seres humanos entre si? Afinal, "a história não conhece verbos regulares" (Thompson, 1981, p. 57).

$\mathrm{Na}$ perspectiva do materialismo histórico e, portanto, na busca incessante de elementos que nos indiquem os movimentos do real, que favorecem a compreensão do concreto como "síntese de muitas determinações, isto é, unidade do diverso" (Marx, 1978, p. 116), que aspectos econômico-culturais de outros modos de vida devemos considerar? Como nos indicou Marx em Para a crítica da economia política,

Assim como não se julga o que um indivíduo é a partir do julgamento que ele se faz de si mesmo, da mesma maneira não se pode julgar uma época de transformação a partir de sua própria consciência; ao contrário, é preciso explicar esta consciência a partir das contradições da vida material, a partir do conflito entre forças produtivas sociais e as relações de produção. (Marx, 1978, p. 130)

Se é o ser social que determina a consciência, parece-nos pertinente perguntar quais são as determinações na constituição da classe trabalhadora hoje. Em Marxismo $e$ literatura, Raymond Willians (1979) analisa que na teoria cultural marxista nenhum problema é mais difícil do que o da "determinação". Explica que o sentido etimológico da palavra "determinação" (determine) significa "estabelecer fronteiras" ou "estabelecer limites" (p. 88). Para ele, "o senso de coisa exterior é decisivo no desenvolvimento do conceito de 'determinismo', no qual algum poder (Deus ou a Natureza ou a História) controla ou decide o resultado de uma ação ou processo, além ou apesar das vontades ou desejos de seus agentes" (Ibid). Ressalta que a questão-chave que merece ser discutida é a proporção em que as condições objetivas são consideradas como externas, pois "por definição do marxismo, as condições objetivas são e só podem ser resultado das ações 
humanas no mundo material" (p. 89). Em Palavras-chave, o companheiro de Thompson no Grupo de Historiadores do Partido Comunista da Grã-Bretanha, adverte que faz parte da história da palavra, o fato dela conter outro sentido: "determinar, determinado e determinação dizem respeito não a limites ou fins, nem a qualquer outra causa externa, mas especificamente a atos de vontade, como "eu estou determinado a fazer isso acontecer." (Willians, 2007, p. 140)

Na perspectiva do materialismo histórico, Thompson reconhece que "objetivo" e "subjetivo" não são entidades dualisticamente separadas; a compreensão da história como processo pressupõe a análise das condições objetivas e subjetivas das situações reais, no contexto em que as experiências emergem. Sendo assim, ganha relevância a ação humana, ou seja, o papel ativo dos homens e mulheres (trabalhadores domésticos, tecelões, sapateiros etc.) no processo de produção da vida social.

Sem aderir ao economicismo ou reducionismo econômico que caracteriza o pensamento de Louis Althusser ${ }^{11}$, Thompson não nega determinações as quais os trabalhadores estão submetidos. Na verdade, esse último autor questiona a metáfora do edifício, em que a superestrutura (formas jurídicas, políticas, religiosas, artísticas e filosóficas, específicas de Estado e de consciência social) constitui-se como o espelho da infraestrutura (conjunto das relações sociais de produção). Ao insistir na relação dialética entre infraestrutura e superestrutura, enfatiza que "se a experiência aparece como determinada, o mesmo não acontece com a consciência de classe" (Thompson, 1987, v. 1, p. 10). No artigo, Algumas observações sobre classe e consciência de classe, analisa que:

A classe se delineia segundo o modo como homens e mulheres vivem suas relações de produção e segundo a experiência de suas situações determinadas, no interior do "conjunto de suas relações sociais", com a cultura e as expectativas a eles transmitidas e com base no modo pelo qual se valeram dessas experiências em nível cultural. (Thompson, 2001, p. 277)

O destaque do autor na citação acima acentua que nenhuma formação social é independente de determinações objetivas e, portanto, a classe não pode ser definida como simples fenômeno cultural. Sendo assim, o que Thompson reivindica é o exame escrupuloso das determinações objetivas, sem o que, podemos cair na tentação de entender a classe como um conceito estático, sem vida. A análise do processo histórico pressupõe o entendimento de como, pela experiência, esses homens e mulheres vivem, percebem, sentem, fazem e refazem o conjunto das relações sociais, determinadas tanto por pressões externas como pela vontade coletiva. Nesse horizonte, os elementos teórico-metodológicos presentes na obra de Thompson contribuem para a análise do sentido histórico das atuais experiências coletivas de trabalhadores, suas raízes históricas e seus campos de possibilidades, tendo em conta a dialética passado, presente e futuro.

Não são poucas as contribuições teórico-metodológicas presentes na obra de Thompson, as quais nos convidam a fazer antigas e novas perguntas sobre o processo histórico e, em especial, sobre as relações entre trabalho, cultura e educação. Para não virar modismo no campo da pesquisa em educação, todo cuidado é pouco! Como nenhuma obra pode ser desvinculada do autor, torna-se imprescindível lembrar que o historiador inglês Edward P. Thompson tem como referência político-epistemológica o materialismo histórico e dialético como método de apreensão da realidade social, que nos ajuda a refletir a realidade atual e o seu vir a ser. Afirma que "qualquer momento histórico é ao mesmo 
tempo resultado de processos anteriores e um índice na direção de seu fluxo futuro." (Thompson 1981, p. 58)

Ao defender a história enquanto totalidade, como uma ciência em construção, como história dinâmica dos sujeitos reais, Thompson trabalha com categorias como expressão das relações humanas. Nesse sentido, "a característica particular do material oferecido ao historiador implica a redefinição das categorias de análise, que se efetua em um movimento dialético do material empírico às categorias." (Thompson, 2001, p. 207). Para isso, privilegia o estudo empírico, a análise do movimento real, sem perder a análise mais ampla da sociedade; não se perde nas reflexões abstratas, gerais, sem sentido, mas também não se limita ao particular e específico, que se constitui na falta de uma crítica global à sociedade capitalista.

Ao incorporar as categorias contradição, singularidade, particularidade e mediação na análise das práticas/movimentos sociais, Thompson contribui para evidenciar a "luta de classes" como elemento de formação da "classe" e, com ela, a "consciência de classe". Para isso, decodifica as formas de expressão simbólica das classes trabalhadoras, entre elas as formas de confronto entre a economia de mercado e a "economia moral" da plebe, baseada nos costumes. Resgata a "cultura popular" como palco da luta de classes.

Como pesquisadores, corremos o risco de fazer generalizações. Nesse sentido, seria prudente "um método lógico de investigação adequado a materiais históricos, destinado, na medida do possível, a testar hipóteses quanto à estrutura, causação etc, e a eliminar procedimentos autoconfirmadores". Para evitar "câimbras teóricas", nada melhor do que o diálogo entre conceito e evidência, no qual "o interrogador é a lógica histórica; o conteúdo da interrogação é uma hipótese [...]; o interrogado é a evidência, com suas propriedades determinadas." (Thompson, 1981, p. 49).

Por fim, cabe enfatizar o que já deve ter ficado evidenciado ao longo do texto, que para Thompson não há neutralidade na ciência. Pelo contrário, exige-se do pesquisador o compromisso com a verdade, o que supõe ir além da aparência, compreender radicalmente o processo histórico o qual se constitui pela ação humana, pelos sujeitos, pela experiência, pela vida material. Thompson acredita que os historiadores devem se preocupar com duas espécies de juízo de valor. O primeiro deles diz respeito aos valores que foram partilhados pelas pessoas que viveram a Revolução Industrial. Para isso, deve-se considerar que "cada um dos dois modos de produção em questão está associado a um tipo diferente de comunidade, como um modo de vida característico" (Thompson, 1987, v. 2, p. 343), o que resultou em tensões e conflitos. O segundo tipo de juízo de valor refere-se ao tipo de envolvimento do historiador ao emitir sua análise sobre o processo global da Revolução Industrial, "do qual nós próprios somos um produto" (Ibid).

\section{Referências}

DEWEY, John. Democracia e educação. São Paulo: Atualidade pedagógica, 1979.

GIARRACCA, Norma; MASSUH, Gabriela. El trabajo por venir. Autogestión y emancipación social. Buenos Aires: Antropofagia, 2008.

HARVEY, David. Condição pós-moderna: uma pesquisa sobre as origens da mudança cultural. 5. ed. São Paulo: Loyola, 1992.

HOBSBAWM, Eric. A era das revoluções. Rio de Janeiro: Paz e Terra, 1991. 
MARX, Karl. Cartas (Marx a Pavel V. Annenkov). In: MARX, K; ENGELS, F. Obras escolhidas. Moscovo: Edições Progresso; Lisboa: Edições “Avante!”, 1982. Tomo 1.

MARX, Karl. Para a crítica da economia política. In: Manuscritos econômico-filosóficos e outros textos escolhidos. São Paulo: Abril Cultural, 1978.

MATTOS, Marcelo Badaró. E. P. Thompson no Brasil. Outubro, São Paulo, n. 14, 2010.

RUGIU, A. Nostalgia do mestre artesão. Campinas (SP): Autores Associados, 1998.

SANTOS, Milton. Por uma outra globalização: do pensamento único à consciência universal. 18. ed. Rio de Janeiro: Record, 2009.

SUCHODOLSKI, Bogdan. A pedagogia e as grandes correntes filosóficas. São Paulo: Centauro, 2002.

THOMPSON, Edward P. A miséria da teoria: ou um planetário de erros. Rio de Janeiro: Zahar, 1981.

THOMPSON, Edward P. Tradición, revuelta y consciência de clase. Barcelona: Editorial Grijalbo, 1984.

THOMPSON, Edward P. A formação da classe operária inglesa. Trad. de Denise Bottmann. 2. ed. Rio de Janeiro: Paz e Terra, 1987. 3 v.

THOMPSON, Edward P. As peculiaridades dos ingleses e outros artigos. Organizadores: Antonio Luigi Negro e Sergio Silva. Campinas, SP: Editora da UNICAMP, 2001.

THOMPSON, Edward P. Costumes em comum. Estudos sobre a cultura popular tradicional. São Paulo: Companhia da Letras, 2002.

THOMPSON, Edward P. Os românticos. A Inglaterra na era revolucionária. Rio de Janeiro: Civilização Brasileira, 2002.

THOMPSON, Edward P. Senhores e caçadores. A origem da Lei Negra. Rio de Janeiro: Paz e Terra, 1987.

TIRIBA, Lia. Economia popular e cultura do trabalho. Pedagogia(s) da produção associada. Ijuí: Inijuí, 2001.

VENDRAMINI, Célia Regina. A relação entre trabalho, cooperação e educação nas pesquisas sobre o Movimento dos Trabalhadores Rurais Sem Terra. Perspectiva.

Florianópolis: UFSC, v.26, n.1, p. 119-147, jan./jun. 2008.

WILLIANS, Raymond. Marxismo e literatura. Rio de Janeiro: Zahar Editores, 1979.

WILLIANS, Raymond. Palavras-chave: um vocabulário de cultura e sociedade. São Paulo: Boitempo, 2007.

WOOD, Ellen M. Democracia contra capitalismo: a renovação do materialismo histórico. Trad. de Paulo Cezar Castanheira. São Paulo: Boitempo, 2003.

\section{Notas}

\footnotetext{
${ }^{1}$ Este artigo tem como referência o minicurso Trabalho, classes sociais e experiência histórica na obra de E. P. Thompson por nós ministrado no GT Trabalho e Educação, na 34 ${ }^{a}$ Reunião Anual da Associação Nacional
} 
de Pesquisa e Pós-Graduação em Educação - ANPEd, realizada em Natal/RN, entre 2 e 5 de outubro de 2011.

${ }^{2}$ Professora da Universidade Federal de Santa Catarina - UFSC. celiavendram@ gmail.com

${ }^{3}$ Professora da Universidade Federal Fluminense - UFF. liatiriba@ gmail.com

${ }^{4}$ Sobre as tentativas de "domesticação" da teoria de Thompson, ver Mattos (2010).

${ }^{5}$ O Luddismo foi um violento conflito industrial de trabalhadores qualificados de pequenas oficinas que reagiam à destruição das oficinas e dos ofícios, com a instituição das máquinas pelo sistema fabril, e à transformação do artesão em assalariado. Conhecidos como destruidores de máquinas, os rebeldes seguiam o general Ludd. Foi considerado por Thompson como um conflito de transição, posterior ao radicalismo popular, ao Jacobinismo e anterior ao Owenismo e ao Cartismo. Tinha feições insurrecionais (motim) e atuava na clandestinidade.

${ }^{6}$ Ver crítica de Newton Duarte: Vigotski e o "aprender a aprender": crítica às apropriações neoliberais e pós-modernas da teoria vigotskiana. Campinas: Autores Associados, 2010.

${ }^{7}$ Ver Jürgen.Habermas: Teoria de La acción comunicativa. Madrid: Cátedra, 1994.

${ }^{8}$ Ver Alain Touraine: Novos movimentos sociais. In: Como sair do liberalismo? Trad. de Maria L. Loureiro. São Paulo: EDUC, 1999.

${ }^{9}$ Ver Domenico De Masi: O ócio criativo. Rio de Janeiro: Sextante, 2000.

${ }^{10}$ Para a crítica às teorias pós-modernas, ver Harvey (1992).

${ }^{11}$ É no livro A miséria da teoria (1981) que Thompson condensa suas críticas à teoria crítico-reprodutivista de Louis Althusser

Recebido em setembro/13

Aprovado em março/14. 